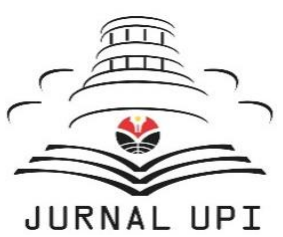

INDONESIAN JOURNAL OF APPLIED LINGUISTICS

Vol. 10 No. 2, September 2020, pp. 460-470

Available online at:

https://ejournal.upi.edu/index.php/IJAL/article/view/28587

https://doi.org/10.17509/ijal.v10i2.28587

\title{
The selection of learning materials from Youtube resources for a Maritime English Course
}

\author{
Nurmala Elmin Simbolon ${ }^{1 *}$ and Yusnita Febrianti ${ }^{2}$ \\ ${ }^{1}$ Marine and Fisheries Department, Politeknik Negeri Pontianak, Jl. AHmad Yani, Pontianak, Kalimantan Barat \\ 78124 Indonesia \\ ${ }^{2}$ Faculty of Letters, University of Negeri Malang, Jl. Cakrawala No. 5., Sumbersari, Kec. Lowokwaru, \\ Kota Malang, Jawa Timur 65145 Indonesia
}

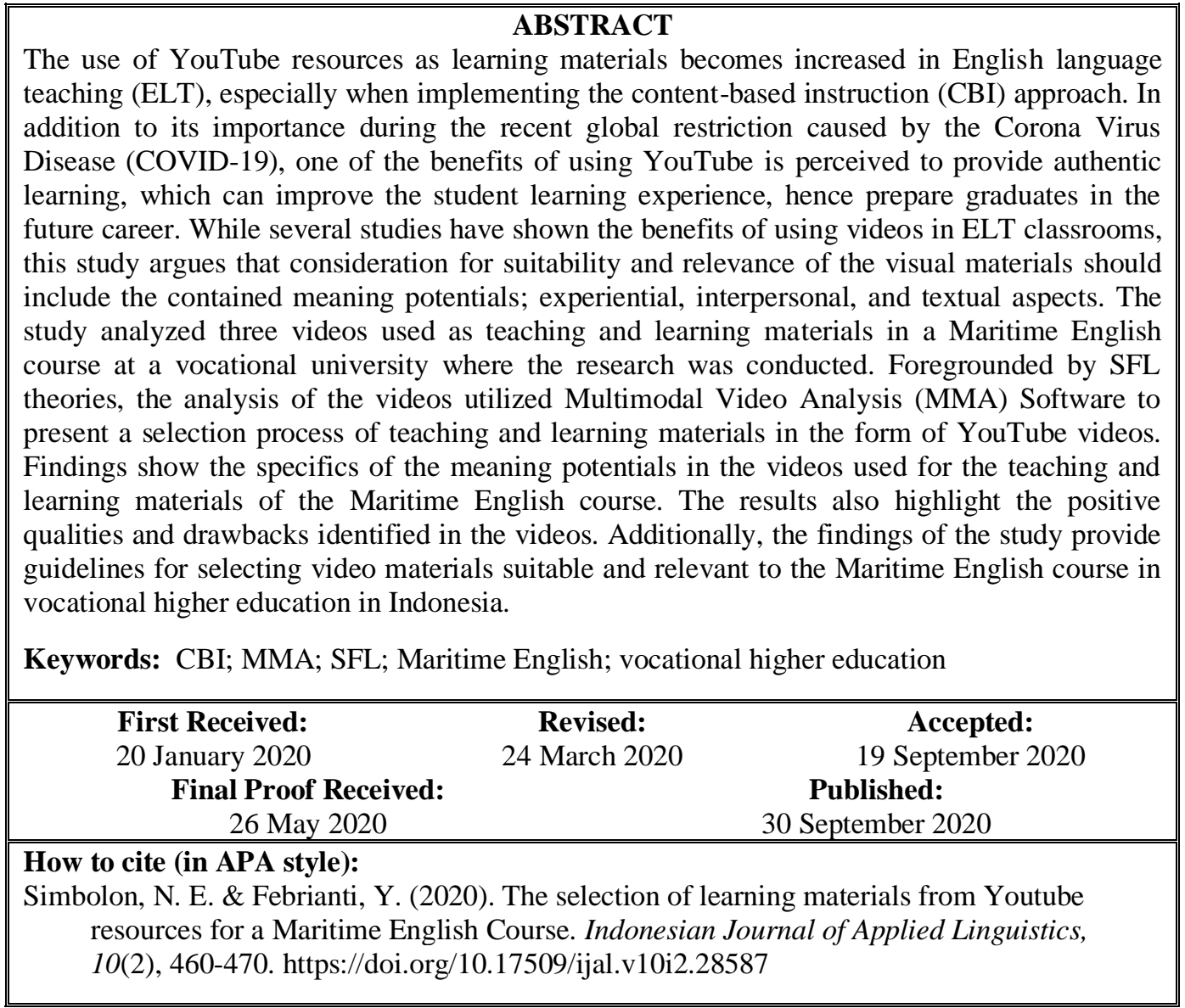

\section{INTRODUCTION}

The use of YouTube resources has been increasingly popular in the education sector in the digital era and especially during the restriction due to the recent global pandemic of the Corona Virus Disease (COVID-19). In English language teaching classrooms (ELT) especially when implementing the content-based instruction (CBI) approach, these free online videos are advantageous in some respects. First, it is the accessibility (Terantino, 2011) so learning can take place in flexible ways. Besides, YouTube gives the authenticity of the materials (Lialikhova, 2014), where the students can experience the most similar context of the future use of the target language, hence connecting to the real world (Joy, 2011). Another positive side of YouTube is the potential to attract learners' attention, focus, and concentration, which can improve attitudes toward learning (Berk, 2009).

But there are some concerns when using videos in ELT classrooms. First, the technical features of a video including its clear picture and sound, as well as the balance between dialogue and visual supports are worth considering. Looking through specific categories of videos such as being top-rated, or most often viewed, is one strategy to selecting videos from YouTube (Berk, 2009).

Another concern is the suitability and

* Corresponding Author

Email: simbolon73@gmail.com 
relevance of YouTube as teaching and learning materials to support student learning. This issue becomes the core of this reported article. Several studies have shown the value of using such video materials in teaching and learning activities, but this research argues that the selection of videos should consider the contained meaning potentials. This meaning-making is mainly framed by systemic functional linguistics (SFL) theory, namely the experiential, interpersonal, and textual aspects in the videos.

\section{Content-based instruction (CBI)}

The Content-based instruction, or CBI is defined as an approach of "the integration of particular content with language teaching aims...the concurrent teaching of academic subject matter and second language skills" (Brinton, Snow, \& Wesche, 1989, p. 2). Several labels have been used to refer to this approach. One of them is content and language integrated learning (CLIL), which is commonly used in Europe (Coyle, Hood, \& Marsh, 2010) with two directions of the continuum; one continuum stresses the course knowledge more; the other emphasizes the language aspect (Ball, 2009). English for Specific Purposes or ESP (Hutchinson \& Walters, 1987 ) is another type of approach of the combining of content knowledge with English learning and teaching. Yet, Stoller (2008) states that CBI is the umbrella term used for the integration of content and language learning. Several models of the CBI approach include adjunct, sheltered, and themebased types. Many ESL and EFL contexts, including the context of the project reported in this paper, use the theme-based model (Stoller, 2002). Referring to the term, this model has a topical syllabus (Stoller, 2002), which students' main content course becomes the guide for English language teaching.

Several studies show the benefits of the CBI implementation at universities. Amiri and Fatemi (2014) conducted a study in a university in Iran by comparing the two different methods of English language teaching, which were the CBI and Grammar Translation Method (GTM). Their study found that students taught using a CBI approach had a higher achievement of their learning than the nonCBI group. There are some factors which may contribute to the different results between the two methods. For example, the learning material used in both was the same, meanwhile the feature of the post-test for both groups of the students seem to be closer to the CBI approach, which benefited the CBI group. The CBI approach appears to present a more comprehensive learning environment like practicing the four language skills, which seem to be scarce in its counterpart method. A more recent study was conducted by Lai and Aksornjarung (2017) in a Thai university. Their study focused on examining students' listening and speaking skills before and after learning in the CBI classroom. The study found that students with low English language proficiency had a more significant improvement in their English speaking and listening skills than those with high proficiency, who showed a significant increase in their speaking. Along with Amiri and Fatemi's (2014) study, their study also suggests potential comprehensive learning of the four skills of language within the CBI approach which benefits in student additional language learning.

However, the challenges of implementing this approach were also acknowledged. One of the concerns in implementing CBI is the determination faced on principles of selecting materials from YouTube resouces. Besides, the linguistic aspect like grammar is necessary to consider. Brinton and Holten (2001) point out the importance of this particular element of the language by highlighting that the CBI curriculum needs to pay more systematic and principled attention to language instruction. Hence, language teachers need sufficient expertise and confidence in language instruction to teach CBI courses (Paltridge, 2004; Simbolon, 2015).

CBI classrooms are featured with the use of a wide range of materials used in the classroom (Crandall \& Tucker, 1990) including YouTube resources. Multimodality and a variety of presentation techniques need to be used in the classes to reduce the reliance on language as the sole instrument of delivering information or demonstrating meaning. Furthermore, the authenticity of learning materials using YouTube resources in the CBI classroom provides language learner with experience in the target use of the language.

Videos are a type of ICT-based resources and multimodal texts. Different modalities, which are images, sounds, and words, are integrated into videos. One of the representations of these multimodal resources is YouTube, which was established in 2005 (Alhamami, 2013). YouTube website is used to upload, view, and share short videos. YouTube has been one of the most popular types of learning resources in education, especially in an online mode during a restriction like the recent global pandemic. These freely available resources offer fast and fun access to language and related-toculture videos from the globe and attract the engagement of many young people (Derewianka, 2008). Some studies on using YouTube in ELT classrooms have been done. For example, a study conducted by Kabooha and Elyas (2015) in Saudi Arabia included 100 female students. The students were divided into two groups: experiment and controlled. Their study showed that the group of students who received learning supported with YouTube learning materials outperformed their fellows of non-experimental class in Vocabulary Knowledge Scale test. Other studies like Lialikhova (2014) and Almurashi's (2016) show similar 
benefits of using YouTube resources in ELT classrooms. The results of Lialikhova's (2014) study showed the improvement of students' vocabulary with videos in the classroom, while Almurashi's study (2016) indicated the positive impact of YouTube resources in helping students' understanding the English lesson. These multimodal media seem to have provided the students in his study with context and visual aids.

However, there are some challenges in using YouTube as learning materials. First, teachers need to work extra time as there are some additional work to do, including previewing and selecting authentic videos suitable for classroom use regarding their language use and context. Another pressure on time would be on the preparation of the activities, based on the selected videos, for their students. Furthermore, using videos may take up too much of the lesson time, especially if videos have a 45minute length of duration, which is one lesson period in a course in this research context. Another challenge of using videos in ELT classrooms can be the potential to a deviation from the main goal educating - which may lead to irrelevance to the desired learning outcomes (Lialikhova, 2014). In the context of this project, many ELT teachers lack sufficient knowledge of content materials and of ways of presenting such materials (Simbolon, 2015). Hence, they need some skills in selecting relevant videos for their classrooms. These issues are focal to this study.

In addition, the issue of subtitle use is important to consider when using YouTube resources for CBI classrooms. Although still debatable, Garza (1991) states that there is a positive correlation between the provision of subtitles and improved comprehension of the linguistic content of the video material. His study suggested that using subtitles in the videos bridges the gap between the development of reading skills and listening comprehension. In his study, students seemed to ascribe meaning to unfamiliar aural vocabulary, which was formerly unfamiliar for them. The learning process appeared to continue when the visual representation of the word was given and, gradually, students built their listening comprehension in relation to their reading comprehension (Garza, 1991). Similarly, Nagira (in Lialikhova, 2014) supports the benefit of using subtitles in videos, especially when learners encounter challenges in understanding appropriate meanings. Hence, subtitles can help in vocabulary growth and retention (Lialikhova, 2014). Once again, this positive result requires teachers' skills, especially in deciding when and how to provide subtitles.

All in all, the concerns of including YouTube resources (picture clarity, sound, and English subtitle use) in the ELT classroom are presented in this article. But, given the positive evidence of the value of using such video materials in the classroom teaching, this research argues that the selection of videos should consider the contained meaning potentials. The meaning-making was mainly framed by Systemic Functional Linguistics (SFL) theory, which are the experiential, interpersonal, and textual aspects in the videos. Thus, this study presents a selection process of ELT materials for a Maritime English course in the form of YouTube, which is framed by the theory of SFL.

\section{Systemic functional linguistics}

Systemic Functional Linguistics (SFL) is a semantic theory of language, which theorises language as context-dependent. The recognition of register variables understands this in the social context, i.e., field, tenor, and mode that shape language functions in any given context (Halliday \& Mathiessen, 2014; Butt, 2000). In the expression levels, these language functions are further realised by experiential, interpersonal, and textual metafunctions, respectively. This means that every text, regardless of their forms, such as images or videos, carries a simultaneous threefold purpose: representing the content of the world (experiential), enacting the relationship of the communicating interactants (interpersonal), and setting the relevant organization in the communication method (textual) (Painter, Martin, \& Unsworth, 2013). While SFL was originally developed to understand language, the development of communication using different modes, such as visual images, graphics, music, and/or and a combination, the theory is applied to the understanding of meaning-making through a combination of language and other modes, which is termed Systemic Functional Multimodal Discourse Analysis (SFMDA) (O'Halloran, 2008).

One of the most current developments in SFMDA is the development of a methodology for the understanding of moving images. One of the latest works is the Multimodal Analysis Video software version 2.0 (MMA) (Multimodal Analysis, 2017). This software, used as the instrument of data analysis, involves a fine-grained examination of a moving-image file, which unfolds the execution of experiential, interpersonal, and textual meanings in video data. This software has been a very helpful analytical tool because it is affordable, user-friendly, and relatively flexible as the system existing in the program can be customised according to the analysis needs (Thwaite, 2015).

\section{METHOD}

This research aims to discuss the issues around the use of YouTube videos as teaching and learning resources. This study seeks to answer the following research questions:

1) What are the experiential, interpersonal and textual meanings from the selected 
YouTube resources that used for the Maritime English course?

2) What are the guidelines for learning material selection from YouTube resources for a Maritime English course?

\section{Research context}

The reported project was done at Borni University (pseudonym), a vocational higher education. One of the specific services of this type of education is to provide its graduates with the technical skills required by the industries. One of the studies offered in the university is Marine and Fisheries. English language teaching at this University adopts the CBI approach. English language course is named Maritime English. When completing their study program, students are assessed with a certification examination to become a seafarer (Read ANKAPIN). The curriculum of Maritime English, mostly assessed in the ANKAPIN English examination, also covers the knowledge of fishing vessel operation and the technology in fishing handling. Students often fail this examination due to their limited English proficiency in those areas. One of the reasons for this failure is suggested as being a lack of relevance in the English language learning materials (Simbolon, 2015), which might hinder students from learning this subject successfully.

\section{Materials \\ This qualitative study (Creswell, 2012) focused on investigating the learning materials, which are in the form of the videos. The videos were recommended by two content lecturers at the University and have been used for the teaching and learning materials in the Maritime English course. Three videos from YouTube, which are labeled Videos A, B and C, were selected for this study. Multimodal Analysis (MMA) (Multimodal Analysis, 2017) was utilised for data analysis. It is a software of video data analysis consisting of a multiple-choice system. The system choices are equipped with descriptions and options that can be practically selected in a single click. In terms of the examination of language, there is a transcription window in the software, that can detail the language elements in a video. The determination of the elements of language use can be made from this transcription.}

\section{Data analysis}

The MMA software aids the analysis with an investigation into the elements that compose the meaning-making resources in the videos. Analysis results from this software helped the study to grasp insights into determining which elements should be present in a video and how these elements could be useful as teaching and learning materials in ELT classrooms. There is substantial number of system choices in the software, so the study selected six system choices representing the quality of elements in the videos, namely: speech function and written language presentation systems for the language element, social distance, visual prominence systems for the image elements, and pace, and volume elements for the sound element (ibid). These systems were selected because they are the key features in each element of a video. Due to space constraints, only two screen captures are produced here, as presented in Figures 1 and 2.

\section{FINDINGS AND DISCUSSION \\ Research Question 1:}

What are the experiential, interpersonal and textual meanings from the selected YouTube resources that used for the Maritime English course?

The findings show that other than being different in length, the distinguishing features between the data lie in the detailed elements of language image and sound in the videos. While the software helps point out the elements with the provided system choices, more details are noted to complete the observation in each video. A broad summary of the observations is presented in Table 1.

\section{Experiential meanings}

The experiential meanings describe the phenomena of the world as categories of experience (Baldry \& Thibault, 2006). In videos, this register is primarily realised by the language and image. While the videos seem to present the language vocabulary related to the terminology of Marine and Fisheries, images that reflect the experiential meanings are found as the synonyms of the wording. See Table 2.

As shown in Table 2 the types of vocabulary used in video A are, for example, fishing vessel, a massive storm, ocean venture, net, chain breaks, fish, boat, sea, and big catch of prawns. Images following the vocabulary are synonymous with those that are presented. Besides, it features images of the whole body of the vessels, the crew members in the ship, the seawater, and the stormy ocean. Video B opens the video with a slide that states: Longline fishing procedures. Then, in the first minutes (up to minute 1.30), the video shows animated images of vessels and the procedures of the longline fishing operation. Towards the middle section of the video, the video shows images of the vessel, its interior parts and the crew members of the vessel. In several slides, the direct relationship between the language and image is quite clear (See Table 3). On the other side, due to a considerable length of absence of language, the experiential meanings in video $\mathrm{C}$ are mostly done through the images. Similar to the other videos, video $\mathrm{C}$ illustrates images of a ship from its interior view, that show the activities of the machinery and the crew's operations in the ship. One remarkable shot in this video is a large number of fish caught and 
stored into the vessel storage. Across the three videos, the images are charaterised with distinct colour contrast and lighting. These systems make the image element distinguishable one from the other.

The language used in the video also creates speech functions, which further feature the types of genre used in the video. In video A, statements seem to be the predominant speech function. This feature is spoken by a narrator, who provides the description of what is going on during the trip at sea. In the beginning, for example, the narrator starts the story by recalling the preceding episode, i.e., "Last time on Solomon, the fishing vessel Amity motion venture battled with a force nine-game". Moreover, several language sources in the form of statements are presented in the form of spoken texts that are delivered by the characters in the video. Video B is also dominated by the form of statements, which ar are featured in the oral texts. The written text in Video B is found as captions in describing the slides and its components. In contrast, there is not much language in Video $\mathrm{C}$, either spoken or written forms. A few uses of language can be found between minutes 24 and 30 of =the video. Furthermore, there are no discernible speech functions that can be captured from this source because the sounds are more like exclamations from the ship's crew giving instructions. See figure 1 and 2 below.

\section{Figure 1}

Sample analysing using MMA for Video B (1)

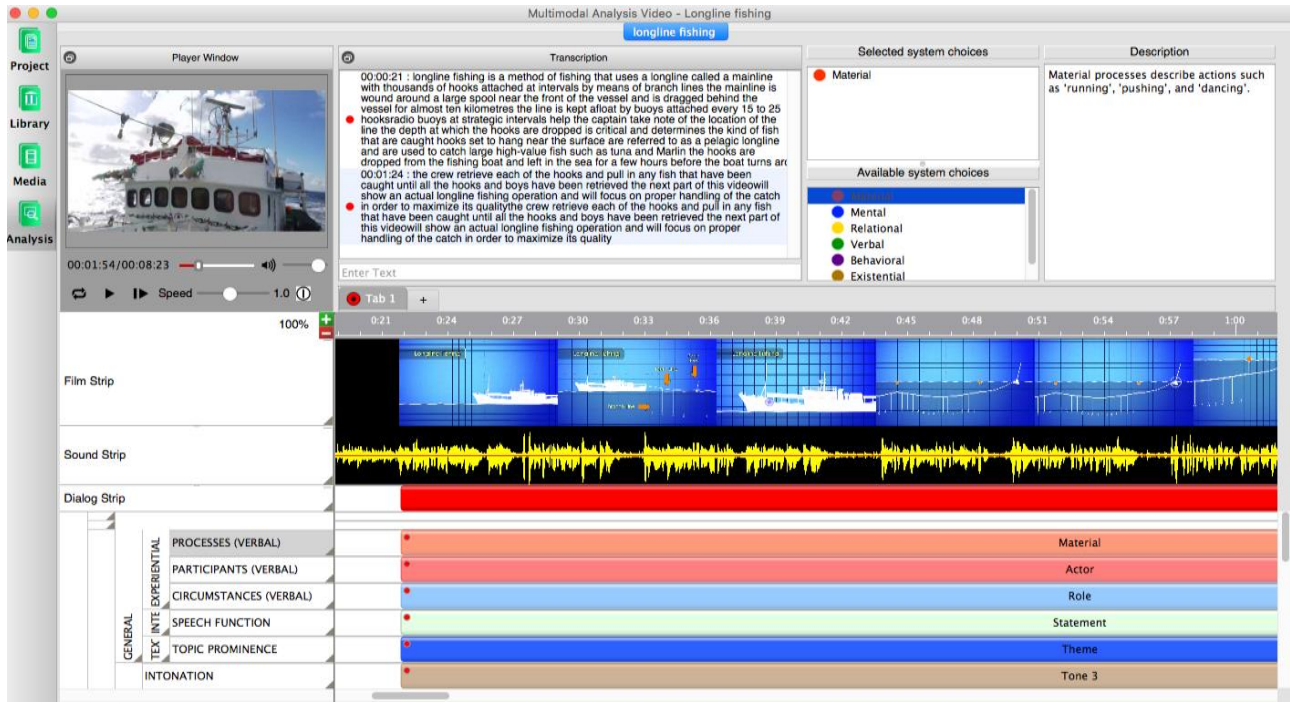

Figure 2

Sample analysing using MMA for Video B (2)

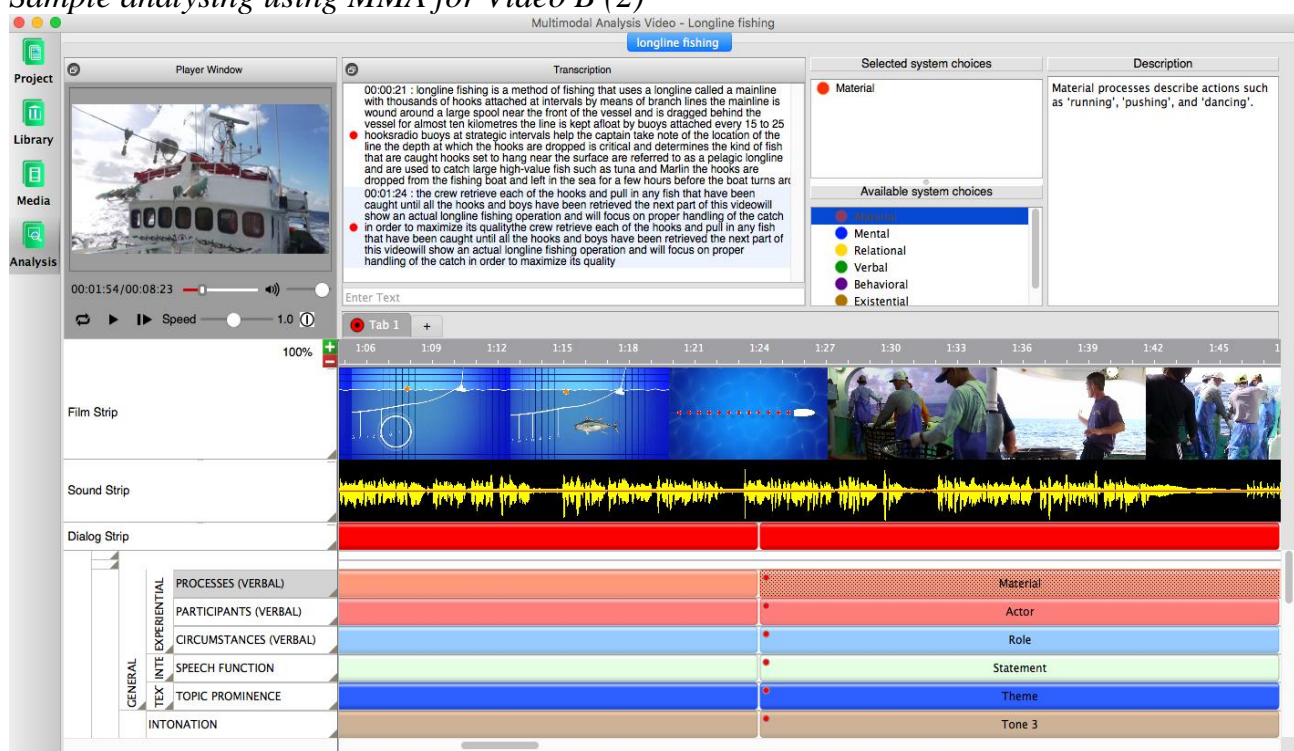


Table 1

Summary of the Observed Semiotic Resources in the Videos

\begin{tabular}{|c|c|c|c|}
\hline $\begin{array}{r}\text { Videos } \\
\text { System Choices }\end{array}$ & $\begin{array}{l}\text { Video A } \\
\text { Length: } 29 \text { minutes }\end{array}$ & $\begin{array}{l}\text { Video B } \\
\text { Length: } 8.24\end{array}$ & $\begin{array}{l}\text { Video C } \\
\text { Length: } \mathbf{3 2 . 5 0}\end{array}$ \\
\hline \multicolumn{4}{|l|}{ LANGUAGE } \\
\hline Speech functions & $\begin{array}{l}\text { Mostly statements (the } \\
\text { language are found from two } \\
\text { sources, narrator's voiceover } \\
\text { and participants' exchanges) }\end{array}$ & $\begin{array}{l}\text { Mostly statements (Spoken } \\
\text { narration is used in describing } \\
\text { the process of longline fishing } \\
\text { and the details) }\end{array}$ & $\begin{array}{l}\text { Command (Spoken exchanges } \\
\text { are found between minutes } 24 \\
\text { and } 30 \text { in the video) }\end{array}$ \\
\hline $\begin{array}{l}\text { Written language } \\
\text { presentation }\end{array}$ & $\begin{array}{l}\text { Found in Title and credit list. } \\
\text { (san-serif design, lower and } \\
\text { uppercase, tight space) }\end{array}$ & $\begin{array}{l}\text { Found in Title, subtitle at } \\
\text { section slide and titles at } \\
\text { descriptive slides (san-serif } \\
\text { design, sentence case, tight } \\
\text { space) }\end{array}$ & None \\
\hline \multicolumn{4}{|l|}{ IMAGE } \\
\hline Social distance & $\begin{array}{l}\text { Eye-level, long shot, medium } \\
\text { shot, and close shot. }\end{array}$ & $\begin{array}{l}\text { Eye-level, long shot, medium } \\
\text { shot, and close shot. }\end{array}$ & Mostly high angled, long shot. \\
\hline Visual prominence & Colour contrast, lighting & Colour contrast, lighting & Colour contrast, lighting. \\
\hline \multicolumn{4}{|l|}{ SOUND } \\
\hline Pace & Conventional, slow. & Conventional & Fast \\
\hline Volume & $\begin{array}{l}\text { Loud, soft (background noise } \\
\text { includes sounds of sea waves) }\end{array}$ & $\begin{array}{l}\text { Loud, soft (background noise } \\
\text { includes sounds of sea waves } \\
\text { and birds) }\end{array}$ & $\begin{array}{l}\text { Loud (background noise from } \\
\text { the engine and mechanical } \\
\text { process of the vessel) }\end{array}$ \\
\hline
\end{tabular}

Table 2

Language and Image Resources in the Videos that Reflect Experiential Meanings

\begin{tabular}{|c|c|c|}
\hline Video & Language & Images $=$ \\
\hline $\mathbf{A}$ & $\begin{array}{l}\text { Fishing vessel, massive storm, ocean venture, net, chain breaks, } \\
\text { fish, boat, sea, big catch of prawns. }\end{array}$ & Synonyms to the language elements \\
\hline B & Longline fishing procedures & $\begin{array}{l}\text { Animated images related to the language } \\
\text { elements }\end{array}$ \\
\hline $\mathbf{C}$ & None & Images of the vessel and the activities in it \\
\hline
\end{tabular}

The experiential meaning in the videos observed for this research highlights two main points: the suitability of the topic and the relevance of the genre types. The language aspect, i.e., the vocabulary as exemplified in the previous section, provides a hint of the topic of the video. Video $\mathrm{A}$ is built on a broad theme of a venture in the ocean and discusses some fishing activities. But, the vide has no specific focus on the topic of fishing. Some of the language use features the inclusion of the crew members' personal lives, such as: "It's not good going home if you haven't made any money, but it's always good to get home". The images accompanying this video are also predominated by close shots that contain the crew's feelings and/or opinions about the fishing trip. Video B explicitly shows hints of the topic by giving the title of the video. The language following the title slide is packed with technical vocabulary relating to longline fishing. Images and the language used throughout the video are much alike. Despite having images highly relevant to the topic of fish catching, Video C lacks the language use resource. In general, the language use that is supported by the images will further establish the construction of genre, which is a useful way of packaging the message in the videos. In the videos observed in this research, a few characteristics of the genre are found. They are recount and narrative in Videos $\mathrm{A}$ and $\mathrm{C}$, and procedure and descriptive genres in Video B.

\section{Interpersonal meanings}

Interpersonal meanings are dealt with the realization of interactions between the participants in the video and between the video and the audience (Baldry \& Thibault, 2006; Kress \& Van Leeuwen, 1996). Both types of interactions are realised, particularly in the use of language. In Video $\mathrm{A}$, the language use changes between being neutral in the narrations and being more personal in the testimonials of the crew members' The narration is characterised by using the address such as "The Ocean Venture" (the name of the ship) to refer to the general idea of the fishing trip. In other cases, the term of address can be found in the speeches of the ship's captain by referring to the crew members "the boys". For example, in Video B, the narrator's descriptions use terms of address relating to the topics, i.e., longline fishing, the vessel, the process, the tuna, the cold storage, and deep-sea fishing.

Also, interpersonal meanings are expressed using images in the videos. The variation of long, medium, and close shots create the distance between the video and the audience. Some examples from the captured frames in the videos are presented in Figure 3. 
Figure 3

Samples of Variation of Shots in the Video Frames

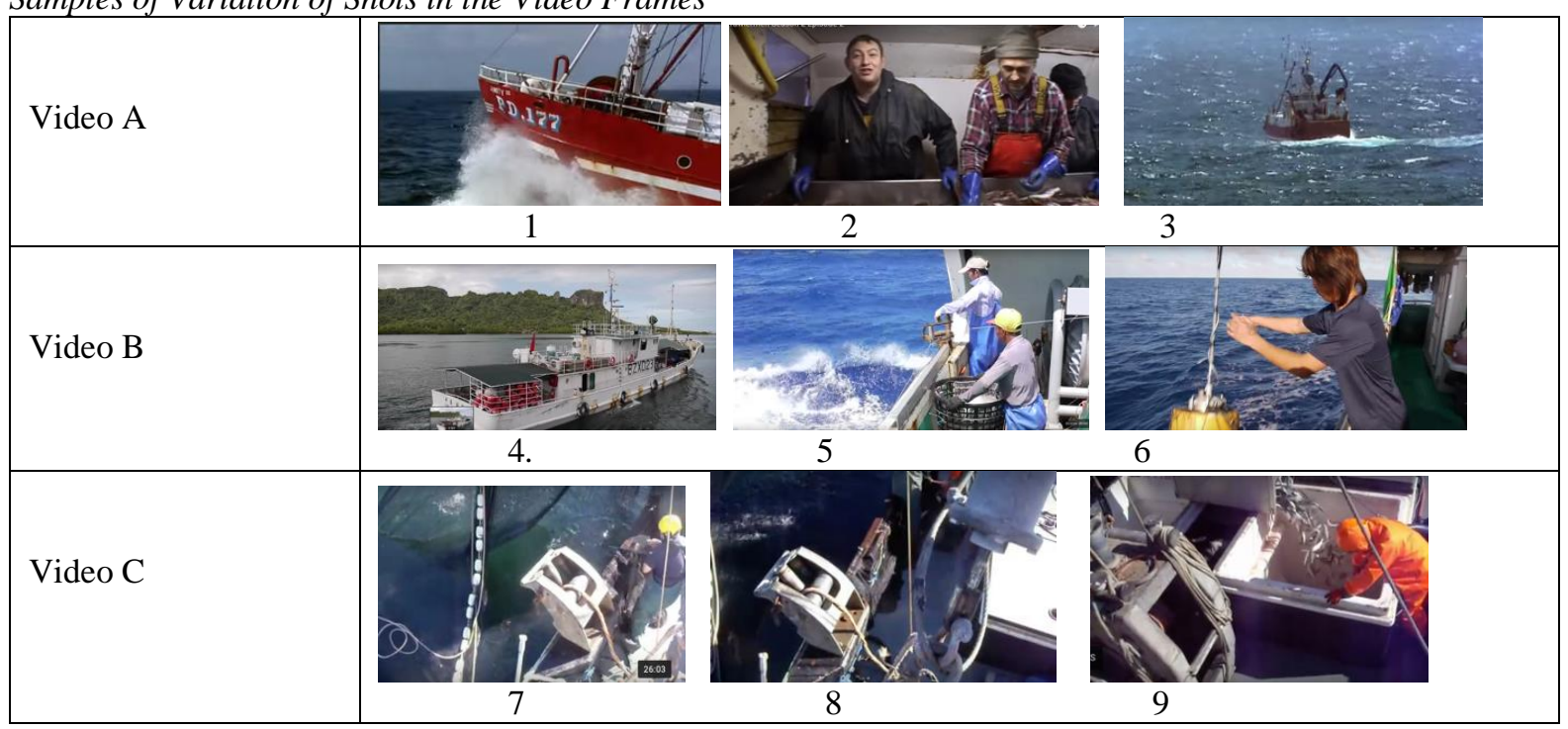

As indicated in Figure 3, frames 3, 4 and 9 are examples of a long shot in which the relation of video-audience becomes distanced. Medium shots in frames 1, 2 and 5 put the videos and audience in an equal position, enforcing the involvement of the audience with the activities illustrated in the frame. A close shot, as in frame 6, reinforces even more involvement for the viewers can see the things the participants in the video are doing.

To some extent, the use of sound also establishes the relationship between participants in the videos. This is exemplified in video $\mathrm{C}$, where we can see the use of loud exclamation from one participant in giving the command to the ship crew, who are pulling the net to collect the yield from the fishing. Overall, the sound elements in the videos consist of two parts, namely the voice and the background music. At a few scenes, background sounds like the sound of sea waves and the vessel's engine also features in the video. The sound elements in the video is set in careful settings of volume, making it possible to discern the sound of the speech and the background sounds such as from the sea waves or the vessels' engine. Hence, these different sound elements can be distinguished from each other quite easily.

\section{Textual meanings}

Every text, including a multimodal text like a video, is organised in such a way that is semantically coherent and related to its context. These textual meanings are realised by the organisation of shots in a video. Video A is of 29-minute length. The sequences in the video are marked by cuts between the scenes. The images alternate between both outdoor and indoor scenes, following the narration given in the voiceover. The total duration of video $\mathrm{B}$ is 8 minutes and 24 seconds. The content of the video is well sequenced into shorter sections, that are longline fishing, actual operation, retrieving catch, pulling in a catch, and safety. These sections are marked using a display of pages which contain the titles of each section. Video $\mathrm{C}$ features a video that is taken in one time of recording. The video contains only one sequence of shots composing the whole length of a 32-minute and 50-second video portraying everything that was going on throughout the total time. The camera moves from one spot to another, but there are no signs of cut scenes throughout the video. The absence of written language texts is another lack of this video, but if on the contrary, Video $\mathrm{C}$ would be the most effective to provide technical terms of Maritime English and authentic feature of the language.

The textual organisation of the video implies two important aspects. First, it ensures the flow of information, i.e., the type of information comes first and follows after. In Video B, for example, the Title is given before the description and images. This organisation provides the audience with background knowledge before moving on to the following information. Secondly, the organisation of information helps to create a reading path, which is important for the students to process the information. Just as when we read, we move from left to right (Kress \& Van Leuween, 1996), the information in a video is arranged to unfold from the first minutes to the following to create a path of 'information' for the audience.

\section{Research question 2:}

What are the guidelines for learning material selection from YouTube resources for a Maritime English course?

It is necessary to note that beyond creating the whole construction of videos, language, image and sound are a manifestation of meanings conveying the whole message in each video. In this project, the 
interpretation of the metafunctional aspects of the video is mapped about the aim of the study, that is highlighting the functions of the semiotic resources in the videos as teaching and learning materials in Maritime English course. As the meaning-making resources in those videos have been outlined, we can simulate the way of selecting the video by reversing the process, i.e., by the consideration of the potential of experiential, interpersonal and textual meanings from a video selection process. Highlighting the positive sides and drawbacks of each video from the perspective of meaning-makings process should precede this consideration. Both sides would suggest the guidelines for materials selection from YouTube resources for the intended course.

Due to its considerable length (32.50 minutes), Video A seems to have many contents. It is designed for a documentary program of a trawlermen ship, the video presents a combination of narration and description in the video. These genres are realised in the use of language, image, and sound featuring multiple complications, for example, it presents the issue with working on fishing ships and the emotional experience of the crew. This video indicates the characteristics of a professionally-produced video, which is intended for, perhaps, a television program. Meanwhile, Video $\mathrm{C}$ seems to be produced by an amateur who uses a mobile gadget. The video is made in a single sequence of the whole 29-minute duration. Both Video $\mathrm{A}$ and $\mathrm{C}$ could be acceptable to serve authentic learning, as suggested by CBI scholar (i.e., Brinton, 2003). However, this resource should be intended for sharing information and not for teaching and learning materials. For the latter purpose, this video is hindered by time and content considerations.

On the one hand, the fact that long duration they have seems to make them unsuitable for the English class session with a 45-minute duration. Using the whole duration of the video means that the teacher will use up the available time allotment. However, using video A to be learning materials for a virtual class, or an enrichment material for students, is considerable. On the other hand, presenting a shorter duration video might encounter another challenge due to the poor sequencing in the video. Also, the complexity of the contents in the videos may suggest a lack of focus on the targeted skills that are expected of students in the teaching and learning activities.

Video B appears to be produced for teaching and learning materials. Despite no clear information, the video seems to be published on YouTube in the category of education. Therefore, the overall design is made in such a way to support learning. For example, there is a sequence in the video and it is marked with some title pages to facilitate the indication in the change of topic sequences. Language, images, and sound elements of this video are carefully constructed to enable students to gain both information and language learning. The language is set to use simple sentences, using simple construction both in active and passive voices. Then, these sentences are spoken with a slow pace, clear pronunciation, and intonation, which is perceivable for students. Instead of video recording, some images are constructed with animation This feature allows for a clear description of a few concepts. The animated images may also be useful in lowering the risk of a realistic view of treatment to animals that might be acceptable for education purposes. For example, the description of the tuna must then be drained of its blood. This is done by stabbing the tuna behind the pectoral on both sides, and by slicing its tail at the lateral line, the video is supplied with the animated image of tuna instead of the live tuna. The monotony of the sound elements result in a beneficial outcome that is leading students' attention to focus on the content language and image rather than the sound. A deliberate matching of the language and image elements in this video has also produced augmented meaning creation that can support students' understanding. Several parts of the descriptions in Video B coincide with the image running in the video. The juxtaposition of language and image enhances the meaning arising in the particular sections. A few examples of the way the language links with the images in the video are presented in Figure 4 below.

The ELT class of this reported research is an EFL context that needs explicit modeling. Therefore, authentic text, may not the top priority in determining the materials used in the classroom. Commonly the preferable videos to use in the classroom are those with good image and better sound quality. Providing these qualities requires practical detachment of language, image and sound so that the makeup meanings in a video can, in turn, make the video visible to the classroom purposes. In summary, the considerations of video selection for the Maritime English teaching and learning activities can be based on the technical measurements of the metafunctional potentials. Table 3 and Figure 4 below summarises the considerations.

In addition to these considerations, it is worth noting that the Maritime English classroom activities in the Maritime English class are bound to the curriculum requirement. The curriculum prescribes that students in this program would be prepared to work in the Marine and Fisheries industry. They are required to master technical terms in the Maritime field, which is measured by the final examination and ANKAPIN certification examination. 
Figure 4

The Juxtaposition of Image and Language in Video B

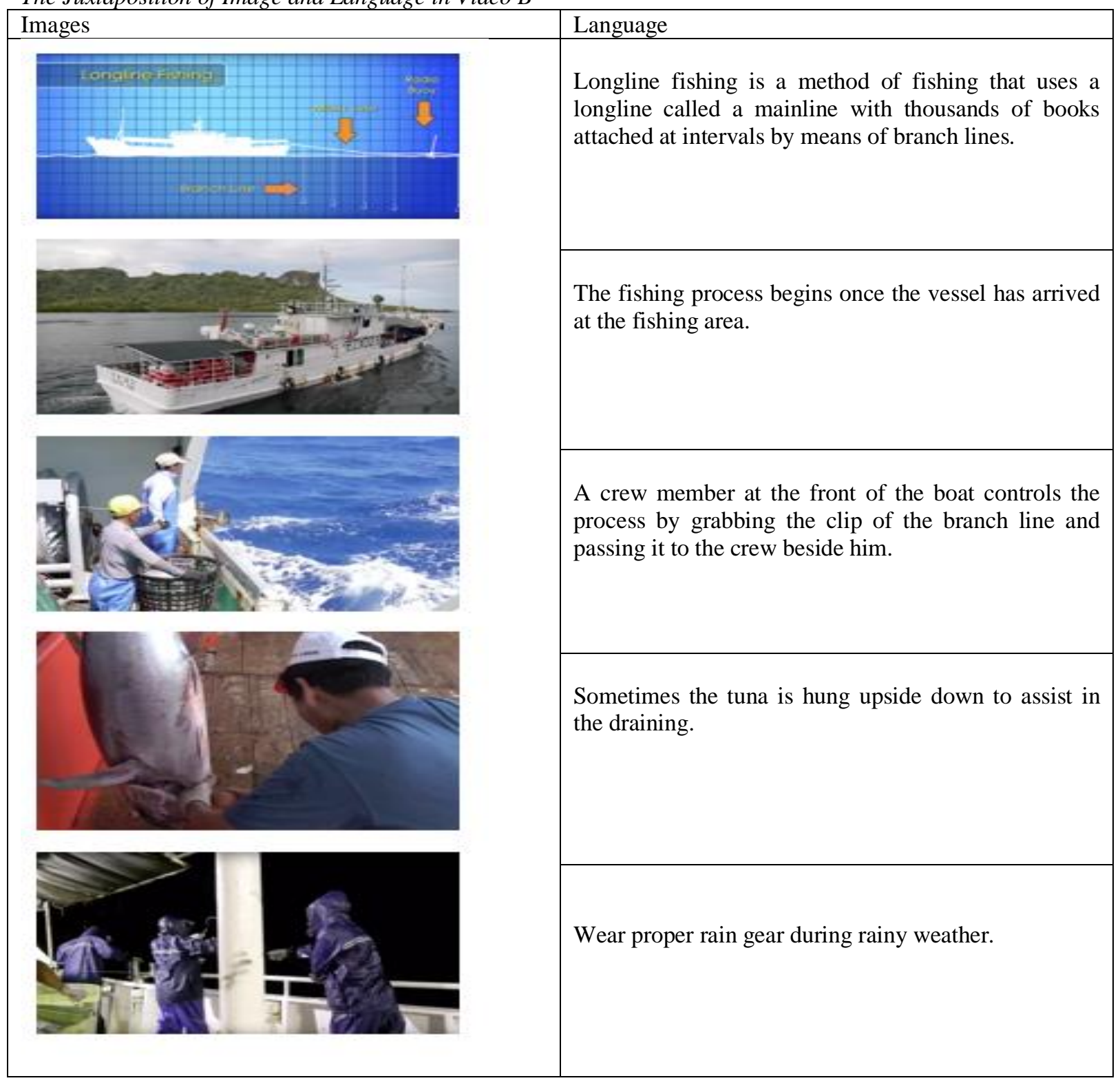

Table 3

The Technical Measurements of the Meta-Functional Potentials for Selecting Videos

\begin{tabular}{|c|c|}
\hline Meta-functions & Video Selection consideration guidelines \\
\hline Experiential & $\begin{array}{l}\text { - The selection of specialist lexis should be suitable to the topic of Maritime } \\
\text { English. } \\
\text { The selection of speech functions should be presented in simple clauses so that } \\
\text { clarity can be ensured. } \\
\text { - The selection of images should represent the identification of the objects as listed } \\
\text { in the specialist lexis and conform to the descriptions presented in the language. }\end{array}$ \\
\hline Interpersonal & $\begin{array}{l}\text { - The selection of pronouns in the language should be neutral to ensure the } \\
\text { objectivity of the video. } \\
\text { The selection of the images the use of various shots should be consider. This } \\
\text { process will allow for the way students relate themselves to the images presented } \\
\text { in the video. } \\
\text { - The selection of sound setting should establish neutrality and clarity. }\end{array}$ \\
\hline Textual & $\begin{array}{l}\text { - The the duration of the video should be included in the selection of video should } \\
\text { consider the. Otherwise, well-sequenced videos should be used so that the each } \\
\text { part of the video can be used gradually. }\end{array}$ \\
\hline
\end{tabular}


Therefore, the selection of videos used for the teaching and learning activities in s but one part of the elaborate preparations for the ELT course to meet the curriculum objective. However, the video selection should ideally conform to the requirements of its curriculum. Hence, the video selection criteria should consider several aspects. First is the curriculum requirements that include the objectives of the syllabus, time allotment of each lesson, the ANKAPIN assessment scope. And then teacher and student capability, i.e., teacher's capacity in preparing a lesson plan, selecting a video, and students' level of English proficiency, is also necessary to take into account. Finally, the availability of facility for the technical presentation of the video in the classroom is as important as the two previous aspects as well. All in all, it is expected that the guidelines proposed in this paper can promote teacher and student autonomy, i.e., the teacher should be independent in determining the selection of videos for teaching and learning materials by focusing what to present and how long to present each (clip) of videos. Students are also expected to manage their independent learning by following the guidelines given in the videos.

\section{CONCLUSION}

The study aimed to investigate the selection process of video teaching and learning materials in a Maritime English course. Three videos were analysed using MMA software. Several main findings were found in this research. First, Various multimodal resources, including documentary, authentic, and work field environments, are necessary to help improve student learning. Furthermore, providing subtitles in YouTube resources can enhance students' learning experience. An option to or not to use them should be related to the learning outcomes of the ELT. And then, the length of videos needs a specific arrangement of the purpose of using them in the classrooms. Another key finding was that the guidelines for the selection of YouTube resources in the Maritime English course classroom were dependent on both language metafunction aspects and requirements of the institution curriculum. In this context of this research, the image and sound of a video seem to precede the authenticity. The study needs evidence of implementing the guidelines proposed from the findings, hence suggesting a need for some studies in this area in the future.

\section{ACKNOWLEDGEMENTS}

I would like to thank Halliday-Hasan International Fund, which has enabled the author to present this paper at the $45^{\text {th }}$ ISFC Congress at Boston College, Massachusetts, the USA, from the $23^{\text {rd }}$ to the $27^{\text {th }}$ of July 2018.

\section{REFERENCES}

Alhamami, M. (2013). Observation of YouTube language learning videos (YouTube LLVS). Teaching English with Technology, 13(3), 317. https://files.eric.ed.gov/fulltext/EJ1144149.pdf

Almurashi, W. A. (2016). The effective use of YouTube videos for teaching English language in classrooms as supplementary material at Taiga University in Alula. International Journal of English Language and Linguistics Research, 4(3), 32-47.

Amiri, M., \& Fatemi, A. (2014). The impact of content-based instruction on students' achievement in ESP courses and their language learning orientation. Theory and Practice in Language Studies, 4(10), 2157-2167. https://doi.org/10.4304/tpls.4.10.2157-2167

Baldry, A., \& Thibault, P. J. (2006). Multimodal transcription and text analysis: A multimodal toolkit and coursebook with associated on-line course. Equinox Pub.

Ball, P. (2009). Does CLIL work? In D. Hill \& P. Alan (Eds.), The best of both worlds?: International perspectives on CLIL (pp. 202222). Norwich Institute for Language Education.

Berk, R., A. (2009). Multimedia teaching with video clips: TV, movies, YouTube, and MTV in the college classroom. International Journal of Technology in Teaching and Learning, 5(1), 121.

Brinton, D. (2003). Content-based instruction. In D. Nunan (Ed.), Practical English language teaching (pp. 78-90). McGraw-Hill Contemporary.

Brinton, D., \& Holten, C. (2001). Does the emperor have no clothes? A re-examination of grammar in content-based instruction. In J. Flowerdew \& M. Peacock (Eds.), Research perspectives on English for academic purposes (pp. 239251). Cambridge University Press.

Brinton, D. M., Snow, M. A., \& Wesche, M. B. (1989). Content-based second language instruction. Newbury House.

Brünner, I. (2013). Using language learning resources on YouTube. In Pixel (Ed.), ICT for language learning (pp. 110 - 115). Libreria Universitaria.

Butt, D. (2000). Using functional grammar: An explorer's guide. National Centre for Language Teaching and Research, Macquarie University.

Crandall, J., \& Tucker, G. R. (1990). Content-based instruction in second and foreign languages. In A. Padilla, H. H. Fairchild, \& C. Valadez (Eds.), Foreign language education: Issues and strategies. Sage. 
Coyle, D., Hood, P., \& Marsh, D. (2010). CLIL: Content and language integrated learning. Cambridge University Press.

Creswell, J. W. (2012). Educational research: Planning, conducting, and evaluating quantitative and qualitative research. Pearson Education, Inc.

Derewianka, B. M. (2008). Venturing beyond YouTube: Learning the language of appraisal. TESOL in Context, 18(2), 42-58.

Garza, T. J. (1991). Evaluating the use of captioned video materials in advanced foreign language learning. Foreign Language Annals, 24(3), 239-258. https://doi.org/10.1111/j.19449720.1991.tb00469.x

Halliday, M. A. K, \& Matthiessen, C. M. (2014). An introduction to functional grammar. Routledge.

Hutchinson, T., \& Waters, A. (1987). English for specific purposes: A learning centred approach. Cambridge University Press.

Joy, J. J. L. (2011). The duality of authenticity in ELT. The Journal of Language and Linguistic Studies, 7(2), 7-23. https://doi.org/10.17263/JLLS.57550

Kabooha, R., \& Elyas, T. (Eds.). (2015). The 8th annual international conference of education, research and innovation. EPALE. https://epale.ec.europa.eu/en/content/iceri2015 -8th-annual-international-conferenceeducation-research-and-innovation

Kress, G., \& Van Leeuwen, T. (1996). Reading images: The grammar of visual design. Routledge/Taylor \& Francis Group.

Lai, Y., \& Aksornjarung, P. (2017). The effects of content-based instruction on listening and speaking abilities of Thai EFL university students. Journal of Creative Practices in Language Learning and Teaching (CPLT), 5(2), 1-20.

Lialikhova, D. (2014). The use of video in English language teaching: A case study in a Norwegian lower secondary school [Unpublished master's thesis]. The University of Stavanger.

Multimodal Analysis. (2017, n.d). Data analysis software. Multimodal Analysis for Critical Thinking. http://multimodal- analysis.com/products/multimodal-analysisvideo/index.html

O'Halloran, K. (2008). Systemic functionalmultimodal discourse analysis (SF-MDA): Constructing ideational meaning using language and visual imagery. Visual Communication, 7(4), 443-475. https://doi.org/10.1605/01.3010011219080.2010

Painter, C., Martin, J. R., \& Unsworth, L. (2013). Reading visual narratives: Image analysis of children's picture books. Equinox Publishing.

Paltridge, B. (2004). Academic writing. Language Teaching, 37(1), 87-105.

Simbolon. (2015). Using the CBI method in teaching English in an Indonesian university. Pertanika Journal of Social Sciences and Humanities (JSSH), 23(4), 1211-1224.

Stoller, F. (2002). Promoting the acquisition of knowledge in a content-based course. In J. Crandall, \& D. Kaufman (Eds.), Content-based instruction in higher education settings (pp. 109-123). TESOL.

Stoller, F., L. (2008). Content-based instruction. In N. Van Deusen-Scholl, \& N. H. Hornberger (Eds.), Encyclopedia of language and education (pp. 59-70). Springer.

Terantino, J. (2011). YouTube for foreign languages: You have to see this video. Language Learning \& Technology, 15(1), 1016.

Thwaite, A. (2015). Using the "Multimodal analysis video" program for register analysis: A preliminary study. TESOL International Journal, 10(1), 110-133.

Links to the video data:

Video A link:

https://www.youtube.com/watch?v=HiI8JFkeF1M

Video B link:

https://www.youtube.com/watch?v=YfGp1Kdf$\mathrm{ds} \& \mathrm{t}=3 \mathrm{~s}$

Video C link:

https://www.youtube.com/watch?v=58IVXAWVsw $\mathrm{k} \& \mathrm{t}=98 \mathrm{~s}$ 